\title{
Utopía del reino y realismo del dolor*
}

\author{
José Ignacio González Faus, \\ Facultad de Teología de Cataluña, \\ Centro de Reflexión Teológica, San Salvador.
}

Comienzo con una rápida confesión. He abordado varias veces el tema de la utopía y el dolor. Casi me aurevería a decir que ése es el tema único de toda teología y que una teología que olvide este tema y no acabe girando en tomo a él se convierte en lo que Lutero calificaba como "imaginaciones de sofistas sobre cosas que les superan" y que "pretenden huir al cielo a base de especulaciones", y no consiguen más que "hacer el juego a Satanás". $O$ en lo que Gustavo Gutiérrez ha caracterizado como "el discurso de los amigos de Job": "consoladores inoportunos" que sólo hablan de Dios para defenderse a sI mismos $^{2}$. Los té́logos del primer mundo no podemos dejar de preguntarnos a cada momento hasta qué punto nuestra teología no es más que ese discurso de los amigos de Job, que el mismo Dios desautorizará al final del drama. Porque eso es toda teología que intente huir de la contradicción propuesta en el título. ¿Por qué, si no, Jesús solla enseñar diciendo que "el reino de Dios se parece a..."?

Una vez dicho esto ya no sé qué más añadir. Lo más cómodo para $\mathrm{ml}-\mathrm{y}$ lo más razonable - sería leer aquí el último artículo que se me pidió para la revista Concilium y que, con otro enunciado, trataba del mismo tema que esta ponencia $^{3}$. A él me remito. Pero, aunque no creo que en esta ponencia consiga más que repetir cosas ya dichas, es innegable que, con el paso del tiempo, algo se mueve en nosotros, y vamos cambiando, enriqueciendo, matizando o corrigiendo. Algo de eso tiene que haberme ocurrido a mí, aunque los otros lo verán mejor que yo. Esto puede dar razón a quienes me pidieron la ponencia. Yo

* Ponencia tenida en Valencia en el congreso organizado por la Universidad Intemacional Menéndez Pelayo, del 9 al 15 de diciembre de 1993, dedicado a La liberación de los pueblos y en homenaje a los mártires de la UCA. 
sospecho que, con el paso del tiempo, lo que me ha ocurido es que se ha ido agudizando la dolorosa tensión entre los dos extremos del título.

Por un lado ha aumentado la desesperación - ino la desesperanza! - por el poder del mal y el realismo que ese poder impone. Tanto que, de entrada, voy a corregir el título que se me dio, y asl quiero hablar de la utopía del reino y del realismo del pecado - no simplemente del dolor, como ahora explicaré. Pero por el otro lado, ha aumentado también el asombro esperanzado por la inexplicable presencia y calidad de la fuerza del reino, en esta tierra maldita. Mostrar eso será sencillamente el objetivo de la presente charla.

\section{La historia como provocadora de la pregunta}

Voy a comenzar evocando algunos momentos históricos que plantean muy bien nuestro tema.

1.1. Imaginémonos en la milad del siglo IV. Hacía sólo trescientos años que un judio desconocido, bondadoso y provocador, había sido ajusticiado brutalmente como si se tratara de una amenaza política espantosa. En el corto lapso hislórico de esos tres siglos, el pueblo que lo ajustició había sido barrido del mapa por los romanos, contra todas sus expectativas religiosas. El resto del imperio había perseguido cada vez con más crueldad a los seguidores de aquel judio ignoto, quienes, a pesar de ello, no paraban de multiplicarse. Ahora, el movimiento que surgió en tomo a aquel Hombre se veía covertido nada menos que en religión oficial del imperio. ¿No es comprensible que los cristianos de entonces vivieran todos esos hechos como la prueba irrefulable de la realización histórica del reino de Dios?

Así lo expresaron ellos. Pero hoy, en la crisis del cristianismo en nuestro primer mundo, aquellos hechos históricos no parecen probar nada. La iglesia que surgí del llamado "giro constantiniano" acabó abandonando esa tensión insoportable entre la ubpía y el realismo. Acabó transigiendo más de la cuenta con el poder y la injusticia, sin los cuales nada funciona. Y camufló esa transigencia con el nombre de Sacro Imperio. Es cierto que se mantuvo la tensión de nuestro tema, pero sólo en los niveles personales (gracia-pecado), no en los niveles propiamente "populares" o "políticos"4. No quiero decir esto criticando, sino tratando de comprender, pero es innegable que tuvo consecuencias fatales.

Así, por ejemplo, el cristianismo primitivo, a pesar de su ruptura con el judaísmo, más que atacar a los judios, había procurado dissinguirse de ellos no hay "sacerdocio" ni "poder sagrado, no hay templo, el Mesías muere identificado con el siervo sufriente de Yahvé, los seguidores de Jesús son tachados de "ateos"... Luego, cuando el cristianismo se habla convertido en sinagoga, fue volviéndose profundamente antisemita'. Y esto nos da paso al otro momento 
histórico que queria comentar.

1.2. Trasladémonos ahora a la mitad del presente siglo. Tras la horrorosa experiencia del holocausto, tras casi veinte siglos del "judio errante", he aquí recién constituido el Estado de Israel. Muchos judios vivieron este hecho como realización de la promesa, y quizás más de un cristiano lo vivió como un cuestionamiento de su fe. Recordemos también aquellos kibuzim y otras primeras realizaciones del nuevo Estado de Israel, que seducian a tantos por su síntesis de socialismo y eficacia.

Y desde ahŕ pasemos a hoy, menos de cincuenta afios después. Aquel Estado-esperanza se ha convertido en vengativo y en terrorista impune. Ha dejado pequeña la ley del Talión y ha despreciado olímpicamente normas internacionales y resoluciones de las Naciones Unidas. Ha creado guetos de palestinos y, como el pueblo del Antiguo Testamento, ha impuesto esclavitudes parecidas a las que él había tenido que soportar, perdiendo las simpatias clamorosas que aglutinaba en los años cuarenta ${ }^{6}$.

Tampoco quisiera decir esto en son de crítica o de condena, sino en son de pregunta. ¿Qué pasa en la historia? He aquí la utopía del reino y el realismo del dolor. Sobre esta contradicción hemos de reflexionar.

1.3. Pero la contradicción aún no está expuesta del todo. Cabc hablar también de que la utopía del anti-reino acaba tropezando igualmente con otro realismo: el realismo de la verdad del reino, que la pone en evidencia. Ese proceso en dirección contraria a los anteriores es también característico del momento histórico que vivimos y, por eso, conviene detenerse un poco en él.

Parece claro que en estos momentos la utopía dominante es la del antirreino: la resignación, la adaptación a la realidad tal como está, y la confimación ideológica de que vivimos en el mejor mundo dentro de lo posible. Se ha aludido varias veces en este congreso al sobado título de Fukuyama: estamos tan bien que puede decirse que hemos llegado al fin de la hisioria. Ya no cabe progresan más sino gozar lo conseguido. V. Renes nota en su libro sobre la pobreza cớnd ya no se habla de "pobres", sino de "menos favorecidos" - y este lenguaje la usan voces oficiales que se encargan de "asuntos sociales"... Ahí tienen ustedes una utopía del anti-reino.

Pero me temo que la crisis económica va poniendo en evidencia a esa pseudoutopía. Ya no estamos tan seguros de que la caida del este haya significar do el triunfo del sistema occidental: a lo mejor lo que pasó es que se rompió d freno del carro capitalista. A lo mejor, el gran valor de los paises del este no fue lo que ellos realizaron $\rightarrow$ ni siquiera aunque Juan Pablo II reconozca que algp bueno hicieron - sino lo que, por miedo, le hicieron hacer al capitalismo. Frena ron su lógica y ahora, perdido el freno, el sistema muestra su verdadero rostro. Nuestros políticos parecen saber ya, aunque no lo digan $\longrightarrow$ sólo lo insinúan art: 
la medida en que va encontrando eufemismos para ello-, que hay que ir al desmantelamiento de todas las conquistas sociales oblenidas por la lucha obrera en los siglos XIX y XX. Hay que llegar hasta ahí porque sólo así podremos ser competitivos a nivel mundial.

Durante la huelga de funcionarios alemanes de mayo de 1992, el presidente de la Daimler-Benz advirtió que la empresa podría reaccionar ante las huelgas trasladando las instalaciones de fabricación de sus automóviles de marca Mercedes a otros lugares, quizá a Rusia con su amplio suministro de trabajadores cualificados, cultos, sanos y -es de esperar-dóciles. El presidente de la General Motors puede esgrimir amenzas parecidas con respecto a México y otros sectores del tercer mundo, y de Europa del este. La General Motors, que piensa cerrar 21 fábricas en Estados Unidos y Canadá, ha inaugurado una instalación de montaje por valor de 690 millones de dólares en Alemania Oriental, con grandes expectativas recalcadas por el hecho de que, gracias a un desempleo no oficial del $\mathbf{4 3}$ por ciento, los trabajadores están dispuestos a "trabajar jornadas más largas que las de sus colegas mimados de Alemania Occidental" a cambjo de un $40 \%$ de sus salarios y pocos beneficios. El capital puede trasladarse con facilidad; las personas no pueden, 0 al menos no se lo permiten aquellos que aplauden las doctrinas de Adam Smith cuando éstas les convienen.

¿Quién puede competir así? Parece como si se estuviera cumpliendo a nivel mundial la dialéctica del "amo y el esclavo" de la Fenomenología del espiritu de Hegel. Si la recuerdan, el amo - "por su falta de miedo a la muerte"- es más audaz, más valiente y acaba sometiendo al esclavo. Pero luego el amo, se dedica a bien vivir y el esclavo a trabajar, con lo que acaba siendo la solución de todos los deseos del amo y éste, que ya no sabe valerse, acaba dependiendo totalmente de aquél. El primer mundo quizás fue más audaz o más criminal $\longrightarrow$ las dos cosas- que el tercero. Lo sometió y ha vivido tan bien, en parte, gracias a él. Pero el tercer mundo se ha hecho de momento más fuerte: es capaz de pasar con muy poco mientras nosolros somos incapaces de pasar ni con un poquito menos -incapacitados además por todo el montaje consumista de la propaganda que se considera necesaria para que la economía tire. Total, no podemos ser competitivos y sólo lo seremos si algunos de nosotros vuelven a las condiciones laborales de los países del tercer mundo... Este es el significado de esos eufemismos: "moderación" salarial y "flexibilidad" laboral. Esta es la lógica del capital. Y notemos cómo hoy, sólo se habla de "solidaridad" para decir a los obreros que acepten recortar su escaso sueldo para que otros puedan trabajar. Los polf́ticos no se bajaron su sueldo de medio millón, recordémoslo, porque eso "no soluciona nada"; y los "socialistas" oficiales que piden solidaridad a los obreros, cuando hablan de lo que les afecta a ellos mismos no hablan de solidaridad, sino de "racionalidad". No tengo nada contra una racionalidad universal; pero cuando se trata de una racionalidad grupal me parece que el lenguaje de los eufemismos ha comenzado a funcionar. 
Esta es la lógica del capital, la utopía de la antifraternidad que acaba siendo puesta en evidencia por la verdad del reino. Y esto no es nuevo. Déjenme evocar para cerrar esta primera parte, el ejemplo de los profetas de Israel. Durante los siglos VIII y VII a. C., en época de bonanza económica, hombres como Amós o el primer Isaías y, más tarde, Jeremías se desgañitaron gritando que aquella bonanza no era una bendición del cielo porque estaba hecha con İa sangre del pobre, con el salario defraudado y con mil injusticias; y que no podía ampararse en Dios porque el templo del Señor no era una cueva de bandidos... Fueron tachados de todo: de utópicos, de irreales, de irracionales, de agentes del enemigo (los asirios, los caldeos o quien fuera)... Pasó el tiempo, y sin que nadie supiera cómo, y contra el principio dogmático que aseguraba que Jerusalén nunca sería conquistada porque Yahvé la protegía, aquel pueblo sordo y vividor, tan duro de cerviz como de bolsillo, se encontró deportado en Babilonia. Entonces comienzan a decir que cómo es posible que Yahvé les haya abandonado... Y entonces la voz de los profetas vuelve a sonar, con tonos muy distintos, en el magnífico poema que hace poco escuchábamos en una de las misas de adviento: "Consuelen, consuelen a mi pueblo, dice su Dios". Para mayor ironía, ese poema se transmite puesto a nombre de "Isaías", el gran fustigador de aquel pueblo antaño.

Aquí tenemos el realismo de la justicia, frente a la utopía de un progreso labrado a base de sangre y opresión. La historia está, pues, transida por esta doble dirección, y esto no conviene olvidarlo. En cualquier caso, la historia sí que justifica que tratemos de reflexionar sobre esta doble dimensión de lo real.

\section{Las razones del realismo}

A mi modo de ver, hay en esta realidad nuestra dos dimensiones o dos componentes que parecen convertir en utópica, o en "fuera de lugar", la pretensión del reino. Creo que es peligroso olvidar una de las dos, porque ello nos llevará fatalmente a un optimismo voluntarista o a un pesimismo condenador y desesperanzado. Antes de comentarlas, las enuncio con palabras de Jon Sobrino: "no ocurre sólo que el mundo histórico no ha llegado todavía a ser lo que debe ser, sino que es, en buena parte, contrario a lo que debe ser"”.

\subsection{La dificultad del "ascenso" ("no ha llegado todavía")}

Formulada con lenguaje teilhardiano, la primera dimensión consiste en la dificultad misma de la empresa. Llevar la materia hasta la vida, hasta la conciencia y hasta la transparencia o universalidad del Espíritu, parecería una empresa absolutamente imposible, si la trayectoria recorrida hasta hoy por la evolución no nos dijera que algunas de esas etapas se han cubierto ya. Esa trayectoria asombrosa va desde el big-bang hasta la conciencia y el saber sobre esa explosión inicial. Este proceso no tiene por qué estar ya acabado. Pero para llegar 
hasta donde estamos hoy han sido necesarios miles de millones de affos, de intentos fallidos, de complejidad lentanente creciente que va consiguiendo almacenar y transmitir, primero información genécica y luego información social o cultural. iTrayectoria asombrosa!

Es conocido cómo Teilhard de Chardin se entusiasmaba ante esa vayectoria hasta postular para toda ella un Omega cristológico y reducir prácticamente toda la no-mundanidad del reino $(J n$ 18, 36) a esa "dificultad del ascenso". Evoquemos también la clásica fundamentación de la historia que daba Ireneo de Lyon ya en el siglo II: el Espiritu necesita tiempo para irse "acostumbrando" a morar en la came, y la came demanda tiempo para irse "acostumbrando" a llevar al Espíritu. Y esto vale tanto a niveles personales como a nivel de la historia total. "Un único Dios que creó la temporalidad para que el hombre fructifique en ella la inmortalidad y entonces El afladirá la eternidad" (AH, IV, 5,1).

Esa calidad y dificultad de la tarea la encuentro bien expresada en estos sencillos versos de Pedro Casaldáliga, que parecen poetizar a Ireneo:

Hablemos de la tarea / de nuestra caducidad

que es hacer que el tiempo sea / Lodo ell, Etemidad.

Parece efectivamente una tarea imposible. Los cristianos creemos, no obstante, que esa tarea ha sido inaugurada ya en la resurrección de Jesús. Pero a menos que desde la resurrección se reciba esa tarea como una gracia, puede convertirse en una locura orgullosa, en una hybris -desmesura - prometeica que lleva su propia calamidad en si misma, sin que haya que recurrir a ningún dios pagano que castigue a Prometeo por el éxito de su empresa.

Sin embargo - y aunque hoy ya casi nadie se atreve a usar la formula del Marx joven, que llamaba a Prometeo "el más grande de los santos del calendario laico"- no puede negarse que el género humano lleva dentro de si la semilla de esa desmesura. La liberación de los pueblos no es una tarea ya terminada como parece pensar Fukuyama, ni tampoco dejada por imposible. Pasara por nujos y reflujos de optimismo y desesperación, pero es como una especie de radioactividad que el ser humano lleva dentro, y que no hay manera de extinguir para escapar a sus radiaciones. Recuérdese todo lo visto en el apartado 1.3.

Aceptando todo esto, acabo de decir que me parece peligrosamente mutilador reducir la dificultad del reino a este solo aspecto. Lo queramos o no, el hombre no tropieza sólo con ese dolor de que "su caducidad deba convertir el tiempo en eternidad", donde hará falta mucho esfuerzo para avanzar apenas un milímetro. La utopía del reino no choca sólo con el realismo del "ascenso", sino con un "descenso" o caida que no parece tener salida posible, y que en la tradición teológica cristiana ha sido llamada "pecado", para expresar que es absolutamente contraria a la voluntad y al proyecto de Dios. Es preciso por tanto dar un paso más. 


\subsection{La "imagen destrozada por la culpa" ("contrario a lo que debe ser")}

Comparemos las ideas teilhardianas que acabo de evocar con un sencillo texto de Kant en el que dice que es mejor no considerar mucho la historia de la humanidad, porque quien lo haga se expone a añadir a ella un nuevo pecado que serla el de odio y desprecio al género humano". Déjenme evocar también un impresionante párafo de Oriana Fallaci, tras su experiencia en el Lfbano, en el que afirma la necesidad de "recuperar la noción crisliana de pecado", aun cuando reconoce que esa noción ha sido fuente de muchos totalitarismos inquisitoriales?.

La ventaja de estas dos evocaciones es que sitúan correctamente la noción de pecado en referencia a la historia. y señalan las falsificaciones que pueden hacerse de esa noción cuando se la saca de la historia y de los sujetos de ella para reducirla a una serie de supuestas transgresiones a una "arbitrariedad divina", diferente de esa voluntad de Dios que ha de hacerse en la tierra como en el cielo, y que consiste en la venida de su reino a esta historia.

Y conste que, al decir esto, no pretendo reducir el pecado a su dimensión meramente política. Personalmente creo que hasta lo más profundo de la intimidad de la persona tiene, a la vez, una dimensión social e histórica. Lo que ocurre es que, si no se percibe esa dimensión, se reduce el pecado personal a una mera "rransgresión" positivista, que puede llevar a la "hipocresia" denunciada por Jesús, y de la que valen también las mismas palabras del Señor: "esto es lo que habia que hacer, aunque sin olvidar lo otro" (Mt 23, 23).

No hay aquí tiempo para hacer una teología del pecado y de su relación con el dolor humano. Muy esquemáticamente me gustaria definirlo como una forma de autoafirmación hecha en contra o al margen de la totalidad. Esa autoafirmación excluyente, implícita o explícitamente excluyente, siempre lleva a la "mentira" y al "homicidio" para decirlo con palabras del evangelio de Juan. O bien a la "ceguera" y a la "condena" del otro, para decirlo con el lenguaje de Pablo ${ }^{10}$.

Como autoafirmación excluyente, el pecado consiste en no escuchar a la realidad. Es lo que Jon Sobrino califica como "falta de honradez con lo real". Y se realiza poniendo toda la racionalidad, toda la écica y toda la religiosidad del ser humano - hábilmente tergiversadas- al servicio de esa opción personal previa Es decir, lo mejor del ser humano, lo que la Biblia llama su "imagen divina", se pone al servicio de una forma de autoconservación que equivale a "querer ser como Dios" (Gen 3, 5).

A partir de aqui el hombre vive segregando justificaciones para esa falsa autoarimación. Una veces para bombardear Irak sin percibir que el no tomarse la justicia por su mano y no ser a la vez juez y parte es la más elemental norma de la convivencia humana Otras veces para lavarse las manos ante Bosnia, 
como si allf no se cometieran crimenes y atrocidades infinitamente más monstruosas que en Kuwait, aunque Bosnia no tenga petroleo. Y todo esto con el agravante de que un crimen de terrorismo intemacional sirve para que un presidente en horas bajas recobre popularidad. Mientras que la pasividad del carn europeo que no escucha la pregunta de Dios "¿dónde está un hermano bosnio?" o que responde a esa pregunta con la eterna respuesta "¿soy yo acaso el guardián de mi hermano?"... es tácitamente aprobada por casi todos nosotros y no encuentra más que alguna voz en el desierto.

O con otras palabras, unas veces se utiliza la imagen divina del hombre y el clamor del reino como excusa para despojar al hombre en provecho propio. Otras veces se utiliza la "dificultad del ascenso" de que hablábarnos antes, para defender privilegios previos y posiciones preestablecidas. De ambas cosas dan testimonio intuitivamente estos otros versos que reproducen la experiencia de Pedro Casaldáliga:

Te llamarán poela / para reirse de tus razones /

que desentonan de su razón; /

para zafarse de tu evangelio / que les cuestiona su propio Dios.

Te llamarán profeta / para exigirte lo que no son /

Para llevarte a la muerte / y darte un poster en su salón".

Unas veces se desautoriza la utopía del reino como "poesía" para dispensarse de su llamada. Otras veces se abusa de ella —como profecía- para asesinar incluso al portador del reino, sin perder por ello la buena relación con El "ponerle un poster" - cuando ya ha dejado de molestar... Quisiera decir todavía una palabra sobre cada una de estas dos zancadillas a la liberación de los pueblos.

a) En el primer sentido - "Ilamar poeta para reírse"-, habría que hacer hoy a la ciencia una crítica muy similar a la que Marx hizo a la religión en el siglo XIX: funciona como ideología legitimadora, como "corazón de un mundo sin corazón". Calificar a algo como "no cienúfico" pone hoy en juego entre los bien pensantes la misma desautorización previa que antafio se ponía calificándolo como no religioso. Una desautorización oportuna que - hoy como ayer- se dispensa así de preguntar si es verdad o no aquello que desautoriza. Y nada de esto constituye un ataque a la ciencia, como tampoco la crítica de Marx tocaba verdaderamente la entraña de la religión. Es su uso $\longrightarrow$ mejor su abuso- lo criticado. Precisamente porque la realidad es dura, la ciencia que intenta conocerla tiene muchas veces aspectos de freno de las utopías. Pero esto no significa que toda resistencia o todo freno sean ya científicos. En este sentido, vale también la parodia de la frase de Marx: "la crítica de la ciencia es la base de toda critica". Pero luego de eso, la ciencia, como la religión antaño, seguirán siendo dignas del más absoluto respeto, si saben purificarse de su abusiva utilización conservadora. 
b) En el otro sentido - "llamarse profeta" o tachar de profeta sospechoso-. baste con evocar la última tentación del ser humano que consiste en la lucha malvada contra el mal. La mitad de los odios, desprecios, violencias y linchamientos que nuestro mundo conoce, provienen de oura forma de autoafirmación excluyente -autodivinización falsa- buscada precisamente en la lucha contra el mal. De esta manera, luchando contra el mal, el hombre queda atrapado en la misma red del mal, empujado a ello por la misma ambiguledad de tantas situaciones IImites. Esto da una idea aproximada del enorme poder del mal. En nuestros dlas, la barbarie del terrorismo puede ser el mejor ejemplo de lo que estoy queriendo decir. Y la lucha noble contra la pretendida moralidad de la pena de muerte, un buen símbolo del camino recto.

Y una última observación, en la que creo yo que coinciden tanto la dificultad del ascenso (apartado 2.1.) como la perversión humana (apartado 2.2.): el mal siempre se estructura. Se puede convertir en fuerza objetivada, impersonal y sin nombre que, por eso mismo, dispone mucho más lácilmente de nosotros. El bien, en cambio, sólo se personaliza y se comunitariza. La estructura puede encarnar el mal, independizada del hombre. Pero no puede encarnar al bien, sino en cuanto asumida por la persona. A lo sumo podrá proteger o intentar evitar el mal. O con otras palabras, una realidad impersonal puede ser muchas veces una tentación o incitación al mal. Pero sólo un testimonio personal puede ser eso que llamamos un "buen ejemplo" o incitación al bien.

Este realismo del pecado viene de lejos en la historia. La tradición teológica, como ya es sabido, habla del pecado "original". Prescindiendo de la exactitud del nombre, no es difícil ejemplificar el proceso a que ahi se alude. La tradición religiosa judeocristiana ha desdivinizado al mundo y con ello posibilitó el progreso técnico. Quizás no es casual que el progreso naciera en occidente y no en otros ámbitos religioso-culturales. Pero el hombre ha utilizado ese progreso cuya posibilidad Dios le entregaba al darle el mundo-, de manera egoísta contra los demás hombres y contra la naturaleza. Nuestro progreso occidental puede ser visto así como el fruto de aquel "árbol de la ciencia del bien y del mal" que queriendo hacer al hombre "igual a Dios", lo desnuda como hombre (efr. Gen 3). He aqui el inmenso poder del realismo del pecado.

\section{La presencia obstinada del reino}

Sospecho que, si le hubiesen propuesto a Jesús de Nazaret el título que se me dio a mí y que habla de "la utopía del reino", el incorregible Jesús habría cambiado también el título y habria hablado de la presencia del reino. Habría hablado asi el mismo Jesús, en cuyo seguimiento creo haber hecho yo todo el ר análisis "desesperado" de la parte anterior..

¿Cómo es posible, después de lo dicho, seguir hablando de "presencia del reino"? Sc trata de una presencia dinámica. Y en los evangelios encontramos 
dos palabras fundamentales para caracterizarla: el reino está presente por su fuerza y por sus señales. Fuerzas y sefiales son las dos palabras que en los evangelios califican los milagros de Jesús: éstos son efectos de la fuerza del reino y seffales de esa fuerza. A través de ellos el reino está presente. Y esas palabras -dynameis y sêmeia - concuerdan con actitudes históricamente garantizadas del Jesús terreno, que se reflejan en frases como éstas: "si tienes fe todo es posible" (Mc 9, 23). Pero además: "si yo lanzo demonios con la fuerza de Dios, es señal de que esá llegando a ustedes el reino de Dios" (Mi 11, 28). Vamos pues a decir una palabra sobre cada una de ellas ${ }^{12}$.

\subsection{La fuerza del reino}

Permítanme otra vez una cita de Casaldáliga. Esta vez de su impresionante Oda a Reagan de la que cstán tomados estos versos:

Habréis embriagado de Cocacola el mundo,

pero queda algún lúcido para deciros ${ }_{i} \mathrm{NO}$ !

El lucro y el poder de vuestras armas

no pueden alcanzar mayor cotización

que el llanto enfebrecido de un niño de color.

¡Qué estupidez o qué voluntarismo o qué ingenuidad pretender que el llanto de un nifno -y además de color - cotiza más que el lucro y el poder de las armas! Y sin embargo, esa estupidez y esa ingenuidad resulta que son una evidencia en la que todos estaremos de acuerdo. Los mismos gestores del lucro y de las armas no se atreverán a negarlo y buscarán modos de decir que precisamente su lucro y sus ammas son medios para evilar el llanto de los niños... La evidencia insobomable de esa estupidez sigue por tanto ahi, juzgando y condenando a un mundo que convierte las más innegables evidencias en desatinos. He aquí un ejemplo de la fuerza del reino.

$Y$ esa fuerza escondida o ese desatino evidente habremos de expresarlos en este mundo con aquellas palabras de Jesús que servirian ahora de comentario a los versos citados de Casaldáliga: "Yo te bendigo, Padre, porque has escondido estas cosas a los 'siete grandes' - a los representantes de los siete países más acaparadores de la tierra- que ahora se reúnen para 'arreglar el mundo'. Y se las has revelado a unos insignificantes del Matto Grosso." Habrá que decir algo de esto, seguramente. Pero eso también tuvo que decirlo Jesús, y lue para él fuente de alegria.

Si el espíritu de Dios abre nuestros ojos para percibir esa fuerza escondida, cambién nosotros le daremos gracias exultantes, aunque ello suponga que, en lo sucesivo, vamos a ser contados entre los idiotas de la tierra, porque el imperio de este mundo no perdona, y además no puede perdonar sin hundirse él mismo. 


\subsection{Las señoles del relno}

Y he aquí que, además, esa fuerza produce de vez en cuando sus pequentos milagros. De vez en cuando hay un ciego que ve, hay un sordo que oye, un paralítico que echa a andar, una piel impura que es purificada, algún demonio arrojado y hasta un muerto que resucita ( $c f r$. Mt 11,5 ). Todos ustedes conoceran alguno de estos signos aunque, por supuesio, nunca aparecen en los medios de comunicación. Y si aparecen, es más bien bajo la óptica de Herodes, que "tenfa curiosidad por si Jesús hacía alguna cosa extrafia" (cfr. Lc 23, 8), de esas que producen ventas y ganan audiencia. Otras veces aparecen como por casualidad, y un ejemplo de esto lo tendrian quienes hace unos dièz antos leyeron aquella historia de horrores titulada Me llamo Rigoberta Menchú y así me nació la conciencia. Que pocos antos despues esa mujer haya recibido el premio Nobel de la paz quizá no resuelve nada, pero es una seffal de que el reino está presente porque este mundo es capaz de contradecirse a sí mismo, o, mejor, de contradecir lo peor de sí mismo, premiando a sus propias víclimas.

Desde esta experiencia de nuestros signos, pasemos ahora a los evangelios. Los evangelios están llenos de narraciones de milagros, demasiados, solemos pensar nosotros que, desde la racionalidad del siglo XX, no sabemos qué hacer con ellos. Están llenos porque el fruto de una narración de ésas debe ser generar esperanza para seguir luchando por el reino, despertar el entusiasmo y las ganas de luchar, porque algo de la utopía del reino puede hacerse presente. Por eso, en el movimiento en tomo a Jesús se conservaron tantos relatos de curaciones y demás. Después, una Iglesia que se habla instalado en el poder, y que ya no era ella servidora del reino, sino que se identificaba con el reino, convirtió los relatos de curaciones exclusivamente en argumentos apologéticos para fundamentar su propio poder. El mundo modemo, que recibió esas narraciones interpretadas como meros argumentos apologéticos, las enfocó así, las discutió sóle desde ahí y ambos - Iglesia y mundo- se perdieron en una inútil confrontación apologética imposible. Nosotros somos hijos de ese malentendido. La Iglesia había olvidado que esas narraciones están en los evangelios para que otras narraciones sigan siendo contadas. Porque la narración motiva; el argumento que no motiva podrá quizás vencer, pero no convencer ${ }^{13}$.

\subsection{La desliguración del reino}

A través de su fuerza y de sus señales, el reino está de algún modo presente y es algo más que mera ulopía. O mejor dicho, lo expuesto nos hace cambiar el conceplo de utopla. La utopía no es lo que no tiene "ningún lugar" -éste es su significado etimológico-, sino lo que tiene su lugar en este mundo, pero negado, reprimido, invadido y dominado por orra fuerza extratla.

Si ahora juntamos esto con lo dicho en nuestra segunda parte, comenzaremos a entender que se trata de una presencia muchas veces desfigurada. He comenta- 
do en otro lugar cómo esta desfiguración se expresa en la Biblia por el hecho de que la salvación y el pecado tienen nombres muy similares, casi iguales. $Y$ que ello es debido a que, en el pecado

el hombre intenta afirmar desde sí mismo lo que en realidad él es desde Dios y como don de Dios: "ser como dioses" es la fómula que describe el pecado de Adán, pero es también el designio de Dios sobre los hombres. Construir una ciudad que empalme la tierra con el cielo aparece como descripción del pecado de Babel (Gen 11,4), pero es también el plan de Dios sobre la humanidad, por ejemplo, la "ciudad futura" de Hebreos 2, la cual no ha sido entregada a los ángeles, sino a los hombres. Este esquema [que los dos ejemplos citados formulan a nivel personal y a nivel social] es central para una visión cristiana del hombre. La cristología pone de manifiesto que el hombre es una pretensión de divinidad, pero que esa pretensión, de hecho, no se da en el hombre histórico sin pecado y muerte ${ }^{14}$. Jesús es una solidaridad total con esa pretensión del hombre (cfr. Mt 5, 48 con Gen 3), aunque no con el pecado que ella implica; pero es una solidaridad tan hasta el fondo, que acepta las consecuencias de muerte que esa pretensión acarrea de hecho al hombre (La Humanidad Nueva, 7a. ed. pp. 595-596).

Aquí se encuentran, a mi modo de ver, la utopía del reino y el realismo del dolor. Por eso, para un creyente será siempre una tarea importante saber discernir cuándo construimos reino de Dios y cuándo construimos torre de Babel, cuándo realizamos nuestra imagen divina y cuándo queremos "ser como Dios". Demasiadas veces la distinción no puede hacerse en forma de "cuándos" o de momentos diversos. Lo más frecuente será que queriendo hacer una cosa hagamos también [algo de] la oura; y Jesús ya advirtió que el trigo y la cizafia son a veces inseparables y que existe el peligro de arrancar aquél por querer arrancar ésta. La historia y la experiencia humana confirman en mi opinión ambas cosas. Por eso, el discernimiento del creyente no habrá de hacerse sólo leyendo los signos de los tiempos y sabiendo cuándo ha de decir sí y cuándo no. Muchas veces habrá de hacerse también bajo la forma de "no apagar el pábilo humeante ni quebrar la caña cascada". Unica forma que -según los evangelios- es la verdaderamente mesiánica.

Es en este contexto de presencia desfigurada del reino como Jesús propone las bienaventuranzas, en las que la ortodoxia cristiana parece creer muy poco, y a las que los cristianos parece que miramos sólo como "texlos litúrgicos", pero no como textos "configuradores de vida", gracias a esa nefasta separación entre liturgia y vida que la misma reforma litúrgica del Vaticano II no consiguió abolir, aunque sí sirvió para ponerla más en evidencia. Las bienaventuranzas son sin embargo la Carta Magna del reino en una situación de antirreino. Ellas unifican a maravilla la utopia del reino y el realismo del dolor. Y este es el último punto que nos queda por considerar. 


\subsection{Las bienaventuranzas: utopía del reino en el realismo del dolor}

En el poco tiempo que resta voy a ceñirme sólo a la versión de Mateo, a pesar de que la versión lucana me parece la de más probabilidad histórica. Las razones para esta opción las he expuesto en otro lugar: las bienaventuranzas de Mateo son bienaventuranzas "de actitud", mientras que las de Lucas son bienaventuranzas "de situación". Jesús debio llamar bienaventurados a los que están en una determinada situación. Mateo aplica la enseñanza de Jesús a los que, ante esas siluaciones (pobreza, hambre, llanto, elc.) reaccionan con una determinada actifud (empobreciéndose por el espititu, sintiendo hambre de justicia, entristeciéndose etc.). Son entonces —como dice Gustavo Gutiérrez- las bienaventuranzas "del discipulado". Y por eso las que más se dirgen a nosotros.

Aceptado eso, sigo la opinión de los que ven en las bienaventuranzas de Mateo un esquema "quiástico" o circular: de tal modo que la primera se corresponde con la última, la segunda con la penúltima, la tercera con la antepenúltima y la cuarta y quinta, que quedan en el centro de este esquema, son las que contienen lo central del mensaje. El "hambre y sed de justicia" y la "misericordia" son lo medular de esta Carta Magna del reino y constituyen el lazo de unión entre los dos temas de esta charla: la utopía del reino y el realismo del dolor.

De acuerdo con esto, "la misericordia no se contrapone a la justicia [como tendemos a hacer nosotros], sino que se realiza como hambre y sed de justicia. Aquí está una vez más la síntesis entre gracia y exigencia que nosotros tendemos a destruir: una misericordia sin hambre de justicia puede quedarse en mera sensiblería interesada. Y un hambre de justicia que no brote de la misericordia se quedará en pelagianismo u orgullo prometeico"15. Por eso -en última instancia-, el realismo del dolor no se contrapone a la utopla del reino, sino que la postula.

Y ahora, con la metáfora clásica de la piedra que cae en el lago, esta centralidad de la justicia-misericordia, va desplegándose en clrculos concéntricos que marcan toda la vida del hombre. La persona marcada por esa misericordia que engendra hambre de justicia, será una persona dolorida porque padece-con (compadece) todo el dolor del mundo (tercera bienaventuranza); pero ese dolor solidario no nubla la vista, sino que la purifica al quemar todo el egoísmo que nubla la razón humana (y del que hablamos en la primera parte de esta charla): ese dolor produce los ojos limpios y la mente limpia (sexta bienaventuranza), que son los únicos que pueden ver la realidad como es y, por eso, ver a Dios desde esa realidad sufriente y en ella. Cito aqul también lo escrito en otra ocasión:

Para la antropolog fa bíblica el hombre no ve sólo con la razón sino también con el corazón. Y éste, cuando no está absolutamente limpio, empaña la 
vista de la razón y le impide ver. Lo primero que no "ve" la mente sucia es a Dios, en el sentido joánico del "conocer" al que aludimos antes ( $c f r$. Jn 16, 3). Y por tanto no le ve aunque afirme creer en El. Y al no ver a Dios como Misericordia y Perdón, no hace caso de la Palabra de Dios que le dice: "quiero misericordia y no sacrificios" (palabra de Oseas que Mateo cita por dos veces), se monta así un dios a su gusto, más interesado en el culto que en la misericordia, y se queda así sin percibir la dimensión más profunda y verdadera de la realidad: la injusticia del dolor y la vocación del hombre a luchar contra esa injusticia ${ }^{16}$.

Desde esta purificación de la mente, el hombre se vuelve activo. Y esta actividad es pacificadora y no-violenta (séptima y segunda bienaventuranzas). "Por un lado, al luchar por la justicia trabaja en realidad por la paz, puesto que la verdadera paz es el fruto de la justicia. Pero, por el otro lado, la lucha por la justicia, como fruto de la misericordia, tiende a ser una lucha pacificadora, no violenta (y ésta parece ser la mejor traducción de la segunda bienaventuranza: 'dichosos los no violentos')"'17.

Esta actividad le reporta al hombre unas consecuencias duras, ante cuya dureza resalta más el veredicto de Jesús que proclama dichosos a los que soportan esas consecuencias: el empobrecimiento y la persecución (primera y octava bienaventuranzas). Da lo mismo que en la última traduzcamos persecución "por la justicia" o persecución "por su fidelidad" (ambas traducciones serían posibles). Lo importante es que se trata de una fidelidad a esta carta magna del reino, y que, por lo que toca a la primera bienaventuranza, su sentido queda ahora claro, más allá de todas las ideologizaciones interesadas sobre la pobreza "de espíritu": son dichosos los que se empobrecen por el Espíritu como consecuencia de su opción por la justicia y la misericordia.

En resumen y volviendo a la cita:

Esta es la actitud de respuesta del discipulado a la situación injusta de este mundo en la que - según Lucas - Dios toma radicalmente partido en favor de los oprimidos, declarándolos por ello bienaventurados. [Con el lenguaje de esta charla: ésta es la actitud del que cree en la utopía del reino, ante el dolor que se impone como realismo.] La misericordia purifica el corazón para ver, y esto lleva a afligirse, a sentir hambre y sed de justicia y a privarse. Todo eso se intenta hacer de una manera no prepotente y creadora de paz. Pero, precisamente por eso, lleva a la persecución, y a la fidelidad incluso en medio de ella. Porque lo que no puede descontar un realismo elemental es la reacción contraria del mundo ante esta actitud ${ }^{18}$.

\section{Conclusión}

Para el objetivo de esta charla da lo mismo que hablemos de gracia y peca-

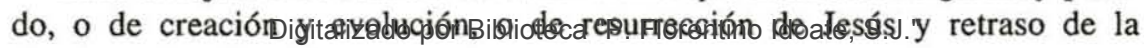
Universidad Centroamericana José Simeón Cañas 
parusía... o que les llamemos utopía del reino y realismo del dolor. Lo decisivo es que el seguimiento creyente de Jesús, y la liberación (de los pueblos, de las clases, de los sexos, de las culturas, de las religiones y de las personas) que es su imperativo absoluto y el sacramento de su promesa, están marcados por esa dialéctica difícil.

Que a lo largo de la historia encontremos oscilaciones constantes entre esos dos extremos no es más que el cumplimiento de una ley histórica detectable en otros muchos campos, y resulta algo demasiado lógico, dada la insuperable parcialidad de todos los momentos históricos, aunque cada momento se crea a sí mismo como "la última palabra" de la historia.

Me pregunto solamente si la tarea del discípulo de Jesús no debería ser, en lugar de dejarse envolver por la moda de cada vaivén histórico, afirmar siempre el polo olvidado: la utopía en tiempos de realismo, y el realismo en tiempos de utopías. Pero intentando afirmarlo - y esto es muy importante- con la suficiente inculturación para que pueda ser comprensible a cada hora histórica el mensaje cristiano sobre el tema que se me ha propuesto: que no es el éxito histórico (que muchas veces sólo se consigue con sangre ajena), sino la sangre derramada que fecunda el futuro, lo que hará que se encuentren la utopía y el realismo, como en el salmo bíblico se besan la misericordia y la verdad, la paz y la justicia (Sal 84, 11).

Algo de eso es lo que me habría gustado saber hacer. Por si no supe hacerlo, déjenme todavía acabar con otras coplillas del maestro Casaldáliga a Francisco de Asís, que se entenderán mucho mejor:

Por acá en la tierra / vamos malviviendo grande la codicia / y el amor pequeño. El amor divino / es muy poco amado, y es flor de una noche / el amor humano.

La mitad del mundo / de hambre se muere y la otra mitad / de miedo a la muerte.

Hay pocos alumnos / que tomen en serio

la sabia locura / del santo Evangelio.

Señora Pobreza / Perfecta Alegría andan en los libros / más que en nuestras vidas...

Nuestra madre Iglesia / mejoró de modos, pero hay mucha curia / y carisma poco... Pactos y tratados / guerras y más guerras. Sangre por petróleo / los imperios truecan. Compadre Francisco / el mundo es tan viejo, que habrá que hacer otro / para verlo nuevo...

Así es, y así sea.

Digitalizado por Biblioteca "P. Florentino Idoate, S.J."

Universidad Centroamericana José Simeón Cañas 


\section{Notas:}

1. Ver p. ej. en la edición de Weimar (WA) 16,217 y $40.1,77$ y 447.

2. Ver Hablar de Dios desde el sufrimiento del inocente, Salamanca 1986.

3. "Nosotros anunciamos un Mesías crucificado" en Concilium, n. 242 (agosto 1992) pgs. 669-682. AquJ tenemos otra vez la utopía del reino ("Mesías"), y el realismo del dolor ("Crucificado").

4. Este es probablemente el significado en la historia de la lglesia de un hombre como san Agustín, extraordinario en lo personal, pero quizás nelasto en lo histórico: e] reino de Dios son s66lo las ideas platónicas. No parece tener ningún tipo de vigencia histórica,

5. En España estamos muy familiarizados con una experiencia semejante: cuando la izquierda se ha derechizado en grande, se convierte en antiderechista demagógica. De modo que el antiderechismo verbal de Alfonso Guerra era algo más que un truco de campaña electoral: yo creo que era el emper̃o imposible de quitar una mala conciencia. La izquierda ya no se distingue de la derecha: por eso habla tanto contra ella.

6. Las líneas anteriores fueron escritas antes de la paz entre Israel y la OLP, que debe ser aplaudida y celebrada, pero no cambia el juicio sobre el pasado.

7. "Religiones orientales y liberación", Cuademos Cristianisme i Justicia, n. 25, p. 20.

8. En la religión dentro de los límites de la razon, Madrid 1986, p. 43. Véase el texto comentado en E. Menéndez Ureña, La crírica kantiana de la sociedad y de la religion, Madrid 1979, p. 29.

9. Inshallah, Madrid 1992, pp. 675-676: "No es posible que el Bien y el Mal estén compuestos de hemoglobina y clorofila... A costa de resucitar a Dios y al diablo..., a costa de correr el riesgo de un nuevo Torquemada, ya que a los torquemadas hemos aprendido a reconocerlos a tiempo y a combatirlos, hay que reinventar el problema moral... Después hay que exhumar la idea del pecado, la conciencia del pecado: explicar que quien hace el mal comete pecado, quien comete pecado debe ser castigado en vida y después de la muerte"...

10. Sobre el lenguaje paulino remito a mi comentario en Proyecto de hermano. Visión creyente del hombre; Santander 1991 (2a. ed.), pgs. 202-216.

11. Este poema se encuentra en Todavia estas palabras (p. 58). El anterior que he citado, en El tiempo y la espera (p. 104). Los otros dos que citaré no los he tomado de ningún libro.

12. Como es sabido, la primera palabra es más propia de los evangelios sinópticos y la otra del cuarto evangelio. Para un comentario más amplio remito a mi estudio sobre los milagros de Jesús: Clamor del Reino, Salamanca 1982, caps. 3, 7 y 8.

13. Al hablar así tampoco niego que pueda ser legítimo un uso "apologético" de los milagros: sólo insisto en que ha de ser secundario e inserto en el marco prioritario de una opción de lucha por el reino. Si se los desgaja de ese marco, y sé convierte el uso apologético de los milagros en objetivo único, se llega a un callejón sin salida.

14. Puede ser interesante constatar que eso que enseña la cristologla parece confirmarlo a veces la psicologfa profunda. El discutido E. Drewerman cree que la autoexperiencia humana radical está marcada por la angustia ante la posibilidad última de "ser en el fondo inútil en el mundo"... "de no ser más que una carga y un estorbo, 
alguien a quien no se desea; más aún: engorroso y hasta nocivo". Teologicamente hablando esa angustia, que tantas locuras nos lleva a cometer, viene a ser la reacción de la imagen divina del hombre ante su limitación creatural. Y es la que lleva al hombre a divinizarse o absolutizarse locamente, para poder justificar su propia existencia y superar asf la angustia. Pero este es un proceso de jadeos interminables en el que el hombre "se elevará a sí mismo o al otro con amor y odio a la categoria de algo absolutum, que pueda proporeionarle una justificación para ser. El conjunto de la existencia humana degenera por ello en un clrculo vicioso de yoidad, en un forcejeo inútil, en un tormento infinito que tiene el valor de una enfermedad y el carácter de una neurosis... [que me hace] encontrarme con el otro sólo en forma de una competencia deletérea, de hostilidad y dominio sadomasoquista o de sometimiento" porque he convertido al otro o a mí mismo en un dios. (Cfr. Strukuren des Bösen, parte Ill. Padertom 1982, p. 571-572). Seria interesante hacer desde aqul una relectura de esa novela (excelente a pesar de todo) que es $\boldsymbol{L a}$ pasión turca de Antonio Gala, y que también podría haberse titulado: "la utopía del amor y el realismo del dolor".

15. "Hacia una cultura del perd6n. La misericordia y las bienaventuranzas como carta magna del creyente". En la obra en colaboración: Iglesia, sociedad y reconciliación, Bilbao 1993, p. 103.

16. Ibid.

17. Ibid., p. 104.

18. Ibid., p. 104. 